\title{
Research on the Adjustment Path of Chinese Pharmaceutical Industry Organizational Structure under the Evaluation \& Approval System Reforming
}

\author{
Jun $\mathrm{Hu}^{1}$, Guangping Wang ${ }^{2}$, Shengyi $\mathrm{Shi}^{2} \&$ Rong Shao ${ }^{1}$ \\ ${ }^{1}$ China Pharmaceutical University, Nanjing, China \\ ${ }^{2}$ Shanghai Institute for Food and Drug Safety, Shanghai, China \\ Correspondence: Jun Hu, China Pharmaceutical University, Nanjing 210009, China. E-mail: \\ 1964009233@qq.com
}

Received: September 7, 2018 Accepted: October 18, 2018 Online Published: October 30, 2018

doi:10.5539/par.v7n2p29 URL: http://dx.doi.org/10.5539/par.v7n2p29

\begin{abstract}
Objective: Drug Evaluation \& Approval System Reforming (EASR) is a major initiative of the State Council's "Delegate power and optimize service" and "random inspection and information disclosure" policies in the R\&D of pharmaceutical industry. The research aims to analyze the impact of drug EASR on the Chinese pharmaceutical organizational structure since 2015. Methods: Based on the relationship analysis between EASR and the organization structure of the government and pharmaceutical industry, this paper uses the Panel Data model to analyze the relevant factors affecting the R\&D organizational structure. Results and Conclusion: The results show that it is significantly and positively correlated between the clinical trial behavior and the technology incubator, the domestic technology transfer and the technology macro environment. The organizational structure optimization path of the pharmaceutical industry based on the EASR includes the specialized division, big data model, international cooperation, MAH and technology finance model.
\end{abstract}

Keywords: evaluation and approval system, drug, organizational structure, adjustment

\section{Introduction}

Evaluation \& Approval System Reforming (EASR) is influencing the innovative development track, the knowledge system of the pharmaceutical industry and the enhancement of core competitiveness. Based on the State Council's "Delegate power and optimize service" and "random inspection and information disclosure" policies, it was raised by the Opinions of the State Council on Reforming the Evaluation and Approval System for Drug and Medical Devices in Aug. 2015 to "improve the quality of evaluation and approval" and "encourage R\&D of new drugs". In June 2017, CFDA (China Food and Drug Administration) joined ICH (International Conference on Harmonization of Technical Requirements for Registration of Pharmaceuticals for Human Use) and became the eighth member globally. At current stage, government institutional reform, two-invoice system and EASR are working together on organizational structure adjustment, innovation progress and performance appraisal; measures of EASR such as MAH (Marketing Authorization Holder) system, GQCE (Generic Quality Consistency Evaluation) and international multi-center clinical data recognition will surely accelerate the course of the Chinese government's functions' transformation and industry's organizational structure adjustment and optimization.

\section{Drug EASR and Supply Side Structural Reform}

\subsection{Overview of Evaluation \& Approval System Change}

The laws and regulations of drug marketing and registration is the core of drug evaluation and approval system. Chinese modern drug regulatory system stemmed from the Drug Administration Regulations (Trial) promulgated in 1978. And after several times' administrative reform of the institution, evaluation and approval system gradually changed from locally decentralized to centralized. New drug was redefined as "not launched home or abroad" from the previously "domestically manufactured and commercialized" in order to propel "encouraging new drug R\&D, making strict the evaluation and approval, improving drug quality and promoting industrial upgrading." The narrowing of the extension of new chemical drugs will force enterprises to pay more 
attention to originality in new drug $\mathrm{R} \& \mathrm{D}$, facilitating the classification and differentiation of pharmaceutical industry and accelerating its transformation and upgrading.

Chinese drug evaluation and approval system came the earliest from Good Clinic Practice (GCP), Good Laboratory Practice (GLP) issued in Aug. 2003 and Identification Method of Drug Clinical Trial Institution Qualification (Trial) issued in Feb. 2004. Data from CFDA Statistical Yearbook showed that 148 clinical trial research bases passed GCP certification in 2013; 27 applied for it in 2016 and in total 449 were qualified by the end of 2016; rather slow for GLP certification in that only 2 passed in 2016 and in total 110 were certified (Figure 1). Number of pharmaceutical manufacturers with R\&D activities increased steadily regardless of the changing in drug evaluation and approval system. In 2016, there existed 1389 manufacturers of chemical drugs, 803 of Chinese patent drugs and 601 of biologics (Figure 2).

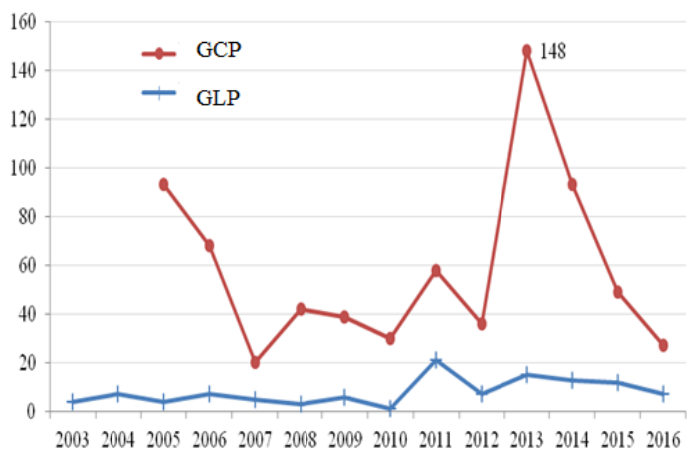

Figure 1. GCP/GLP certification status in 2003-2016

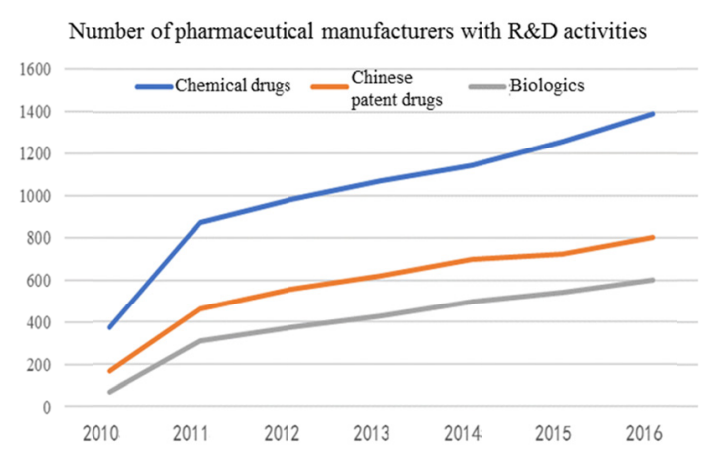

Figure 2. Number of pharmaceutical manufacturers with $R \& D$ activities

Under the trend of global economic integration, "simultaneously developing drugs globally" has become a strategic choice. Drug regulatory authorities worldwide have all been actively exploring drug EASR measures adapting to it. The US government promulgated FDA Safety and Innovation Act and 21st Century Cures Act in 2012 and 2016 while CFDA authorities actively promoted EASR. ICH members such as FDA, EMA and PMDA all adopted a progressive review model for clinical applications and conducted "record before evaluation" or "quick approval". CFDA, as a member of ICH, also adjusted drug evaluation and approval system to adapting to ICH rules.

\subsection{Key Issues in EASR}

The policy document of drug EASR was derived from the reformational deployment of "deepening the reform of administrative approval system". The key issues of drug EASR include centralized approval, MAH system pilot, narrowing new drug definition, globalization of innovative activities and so on. In Jun. 2016, CFDA clarified the top design of drug regulatory system as "the approval of product marketing mainly by country, the supervision of manufacturers mainly by provinces, and the supervision of sales companies mainly by cities or counties", which has been influencing pharmaceutical industry's organizational structure optimization road and method . Furthermore, MAH pilot is a critical part of drug EASR. It will be beneficial to drug R\&D institutions and researchers to actively develop new drugs, and will also be beneficial to industry organizational structure and resource allocation optimization, propelling specialized division and increasing industry concentration.

Changes in drug EASR and globalization of innovative activities are continuing to deepen. FDA Safety and Innovation Act proposed a green channel for new drugs marketed as "breakthrough therapy" while 21st Century Cures Act advocated "real world data and evidence". Both have driven the changes in drug EASR worldwide. The Chinese government was also actively promoting EASR at a policy level of pharmaceutical innovation and development. In Aug. 2015, the State Council issued Opinion on Reforming the Evaluation and Approval System for Drug and Medical Devices, clarifying the tasks to "improve drug approval standard, push forward GQCE and accelerate new drugs evaluation and approval". In Jun. 2017, CFDA began to coordinate clinical trial data standard. In Oct. 2017, the State Council's Opinions on Deepening EASR and Encouraging the Innovation of Drugs and Medical Devices raised the tasks to deepen reform, such as "to reform clinical trial management, to strengthen full lifecycle management and so on". 


\subsection{Evaluation and Approval System \& Government Organizational Structure}

With the reform of drug administration management system and the transformation of government functions, esp. EASR, the relation between government, corporation and society will be reshaped, and the organizational restructuring and evolution process will accelerate at the same time.

Till July 2015, the Chinese government had been carrying out a special rectification action for the verification of drug clinical trial data for two years in the session of drug marketing authorization management (Figure 3). It helped to eliminate the integrity problem during corporation's R\&D in drug evaluation and approval; number of new drug application within China decreased from 2674 in 2015 to 626 in 2016; drug supplementary application appeared to account for a large proportion among drug administrative acceptance matters; the application of the manufacture of generics dramatically decreased due to GQCE while the number of the registration of pharmaceutical packaging materials didn't change much (Figure 4, Figure 5).

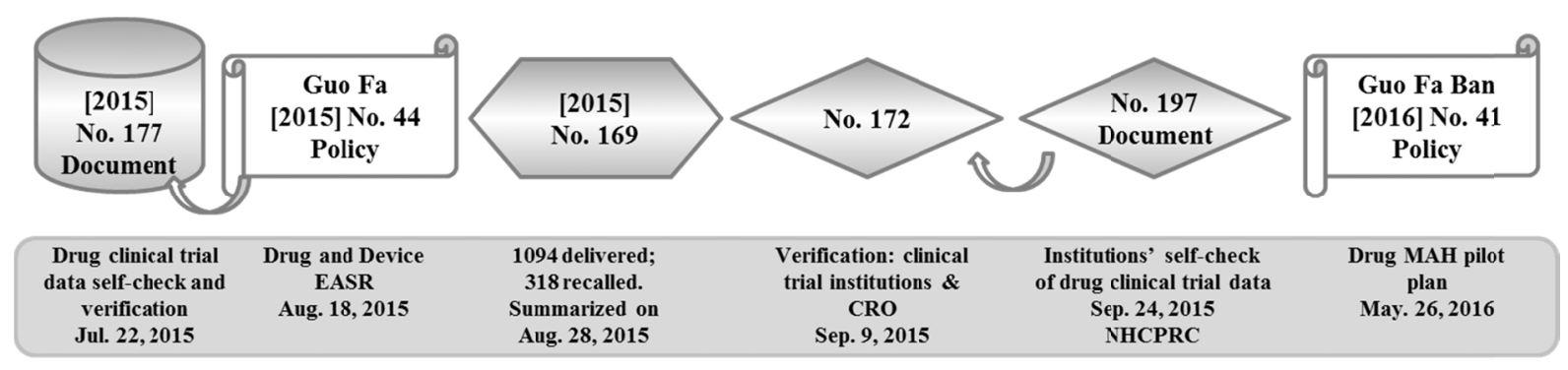

Figure 3. EASR \& special action for data verification in 2015-2016

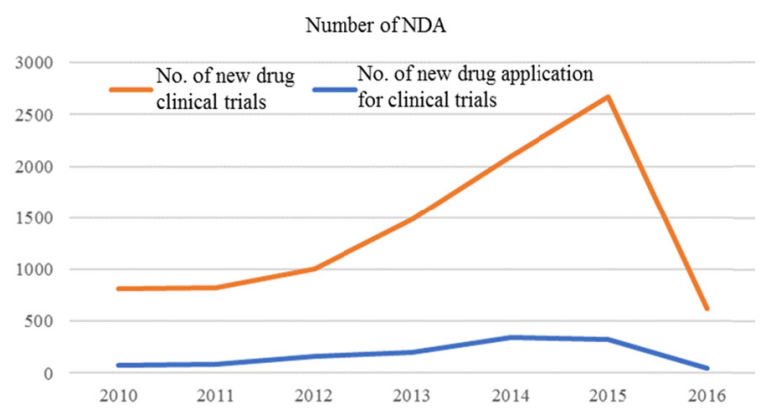

Figure 4. Number of NDA

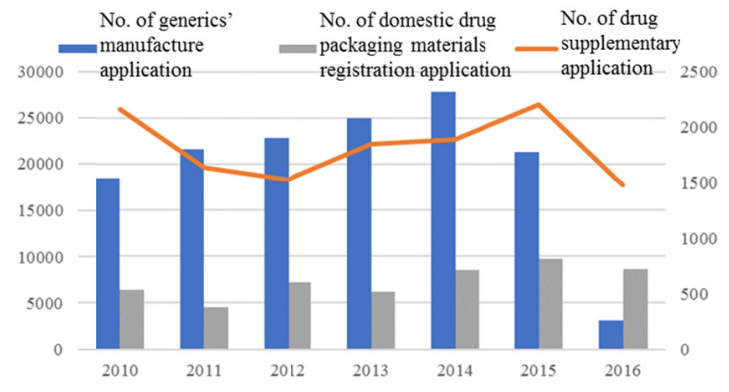

Figure 5. Number of generics' manufacture application, packaging materials registration and drug supplementary application

The progress of drug EASR by the Chinese government since 2015 directly impact structural transformation of the $R \& D$ pattern in medical innovation process, $R \& D$ resource allocation and so on. Organizational forms such as CRO related to clinical trial, CMO in manufacture stage and data service in R\&D stage became especially active. The unbundling of marketing authorization from manufacture authorization by MAH especially changed the dominant position of the state-owned R\&D institutions' and social organizations' market conduct, stimulating and accelerating the organizational restructuring and evolution of the pharmaceutical industry.

\section{EASR and Industry Organizational Structure Adjustment}

\subsection{Overview of Pharmaceutical Industry Organizational Structure Adjustment}

Organization refers to the complex communication pattern and other relation within groups (Simon, 1957) ${ }^{[1]}$. Organizational structure plays a fundamental role in the complex giant system of society. The Chinese government's adjustment of the pharmaceutical industry's ownership organizational structure is a kind of government's him-organized form. It focuses on the mixed ownership reform of those state-owned corporations. It makes corporation conduct rationalized and commercialized through both organizational structure adjustment 
and the institutional arrangement of state-owned corporations' mixed ownership reform, bringing into play the active and leading role of state-owned pharmaceutical corporations in the market in drug EASR.

The number of drug manufacturing certificates and API (Active Pharmaceutical Ingredients) and preparations manufacturers from 2010 to 2017 showed that it decreased in 2016 and 2017 due to the impact of EASR and GQCE. That's why there generally still exists big pressure in drug manufacturers' organizational structure adjustment (Figure 6). The number of drug trading corporations grew steadily from 2010 to 2017 due to the implementation of two-invoice policy and the application of information technology. It will propel the organizational structure adjustment in drug trading (Figure 7) and will react to the organizational structure evolution progress in R\&D.

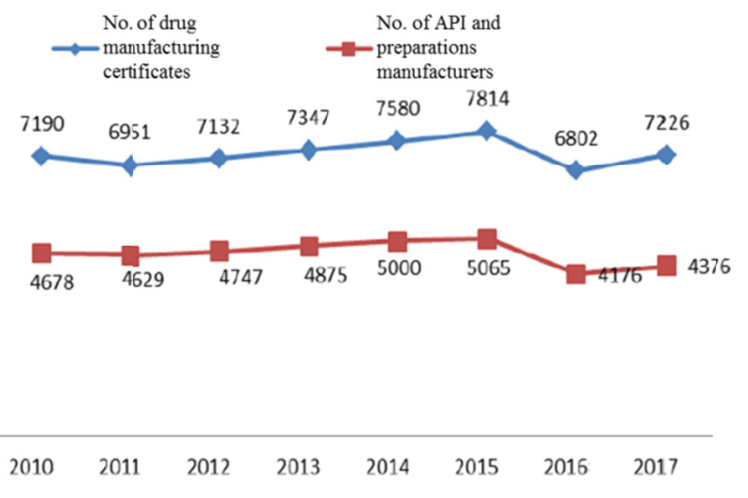

Figure 6. Number of drug manufactures in 2010-2017

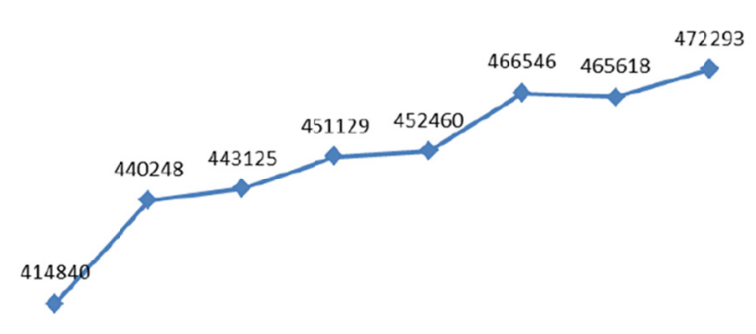

$\begin{array}{lllllll}2010 & 2011 \quad 2012 \quad 2013 \quad 2014 \quad 2015 \quad 2016 \quad 2017\end{array}$

Figure 7. Number of drug trading corporations in 2010-2017

\subsection{Evaluation and Approval System with Specialized Division}

The drug discovery research is the key to improve pharmaceutical companies' core competitiveness, the strategic commanding height in the pharmaceutical industry competition among countries worldwide, also the basis to deepening science and technology system reform during the 13th Five-Year Plan and implementing the development strategy of propelling new biomedicine innovation. EASR resulted from both the government top-down institutional transplantation and the contradiction between the specialized division of pharmaceutical industry and the lag of evaluation and approval system.

Data from the Yearbook of Science and Technology of China showed that number of legal entities in the industry of scientific research and technical services in Beijing, Shanghai, Jiangsu, Zhejiang and Guangdong ranked in the forefront in China and continued to grow from 2011 to 2016 (Figure 8) while Jiangsu, Guangdong, Shandong, Zhejiang and Shanghai led in number of technology business incubators and also continued to grow from 2011 to 2016 (Figure 9). From the results of science and technology output by various provinces and cities, the number of contracts in technical market of Beijing, Jiangsu, Shanghai, Shandong, Hubei and Shanxi was significantly higher than other provinces' and cities' (Figure 10). In the aspect of export-oriented technology, the cost of introducing foreign technology is higher in Beijing, Shanghai, Jiangsu, Guangdong and Chongqing; the cost of introducing foreign technology into pharmaceutical industry is higher in Hubei, Jiangsu, Zhejiang, Shandong and Hebei (Figure 11). Therefore, the performance of pharmaceutical industry development somewhat has a causal relationship with the results of social specialized division of both technology service industry and technology incubators. 
No. of legal person in scientific research and technical services by region

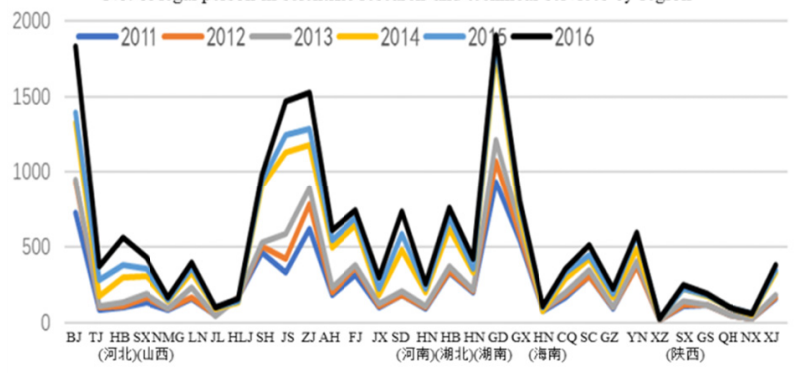

Figure 8. Number of legal entities in scientific research and technical services industry in 2011-2016

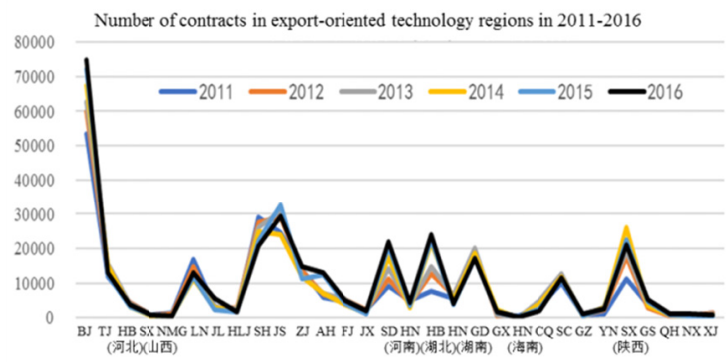

Figure 10. Number of contracts in export-oriented technology regions in 2011-2016

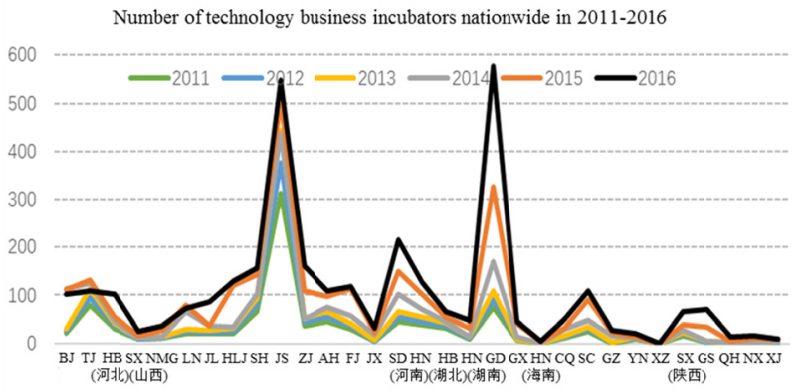

Figure 9. Number of technology business incubators nationwide in 2011-2016

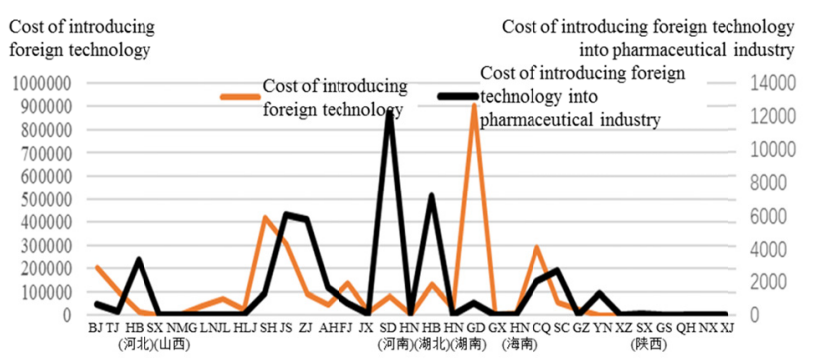

Figure 11. Cost of introducing foreign technology in 2016

\subsection{The Trend of Institutional Transform and Supply Side Reform}

The restructuring of pharmaceutical industry is, in a macro view, mainly the adjustment of regional structure; in a meso view, the adjustment of organizational structure and technical structure; in a micro view, the merger and reorganization of pharmaceutical corporations, that is, the adjustment of corporation ownership structure. The Chinese government's direction of drug EASR and institutional arrangement comes from regulatory authorities of European and American government and the ICH related guiding principles. CFDA and FDA are similar in accelerating approval, encouraging innovation, improving drug quality and so on. From America's 21st Century Cures Act, FDA is more focused on the real world clinical trial data and easy-to-use R\&D and manufacture principles while the Chinese government focuses on evaluation and approval of organizational design, resource allocation, traditional medicine and so on, especially reflected in the MAH system, GQCE and innovative chemical drug definition (Table 1). A series of ICH's guiding principles concerning quality, safety, effectiveness and multidisciplinary synthesis will be organizational code of conduct for innovation activities in China's pharmaceutical industry. Furthermore, in Mar. 2016, the General Office of the State Council issued the Guiding Opinions on Promoting Healthy Development of the Pharmaceutical Industry. It proposed to "strengthen technological innovation, improve core competitiveness, accelerate quality upgrading and promote green and safe development". The above various policy documents and institutional reforms have highlighted the changing trend in drug EASR, which will certainly have a significant impact on the supply side structural reform in pharmaceutical industry. 
Table 1. The institutional arrangement of evaluation and approval system of FDA and the Chinese government

\begin{tabular}{|c|c|c|}
\hline & $\begin{array}{c}\text { 21st Century Cures } \text { Act } \\
\text { (Take FDA as an example) }\end{array}$ & $\begin{array}{l}\text { Deepening EASR and Encouraging the } \\
\text { Innovation of Drugs and Medical Devices } \\
\text { (Ting Zi [2017] No. 42) }\end{array}$ \\
\hline $\begin{array}{l}\text { Key } \\
\text { Points }\end{array}$ & $\begin{array}{l}\text {-Patient centric drug R\&D (ePRO) } \\
\text {-Real world data and evidence } \\
\text { - Product full lifecycle management } \\
\text { (pre-market evaluation and post-market } \\
\text { supervision) } \\
\text {-Drug R\&D tool; continuous } \\
\text { manufacturing (AI) }\end{array}$ & $\begin{array}{l}\text {-Reform of clinical trial management } \\
\text { (recording system) } \\
\text {-Speed up evaluation and approval for } \\
\text { marketing } \\
\text {-Propel drug innovation and generics } \\
\text { development (patent linkage system) } \\
\text {-Strengthen full life cycle management (MAH) }\end{array}$ \\
\hline Features & $\begin{array}{l}\text { - Legal authorization to obtain funding } \\
\text { - Evaluation acceleration (breakthrough } \\
\text { therapy) } \\
\text { - Clinical data regression (ePRO, real } \\
\text { world) } \\
\text { - Quality improvement (special } \\
\text { prescription traceability, Drug Supply } \\
\text { Chain Security Act 2014) }\end{array}$ & $\begin{array}{l}\text {-Centralization of marketing and registration } \\
\text {-Drug administration organization and } \\
\text { personnel reform (every } 5 \text { years) } \\
\text {-Simplified standards for classic prescription } \\
\text {-Strict clinical trial data } \\
\text { Associated evaluation of pharmaceutical } \\
\text { packaging materials }\end{array}$ \\
\hline
\end{tabular}

\section{The Evolution of Pharmaceutical Organizational Structure based on Evaluation and Approval System}

\subsection{Research Progress}

In the neoclassical enterprise theory, corporation is regarded as a single agent, that is, enterprise is analyzed as a black box; but Coase ${ }^{[2]}$ (1937) attributed the market effectiveness and the contradiction between corporations in reality to the existence of transaction cost, thus revealed the contractual nature of enterprise; the emergence and development of corporation was the result of internalization of market transactions. Williamson ${ }^{[3]}$ (1985) and Klein $^{[4]}$ (1978) raised various organizational structures such as developing markets, corporation or bureaucrats, hybrid forms, and bureaucratic organizations. Malerba ${ }^{[5]}$ (2006) systematically described and summarized the intrinsic factors that influenced industrial evolution and technological change. Domestic scholar Zhang Weiying ${ }^{[6]}$ (1995) studied the institutional arrangement of corporation ownership in market economy; Yang Ruilong and Zhou Ye'an (1997) believed that the optimal governance structure of corporation should be allowing key stakeholders to jointly manage a corporation. Lin Yifu ${ }^{[7]}$ (1997), Zhang Jun (1994) and Xi Youmin (2000) conducted qualitative analysis and empirical research on corporate governance and institutional arrangement revolving around the reform of state-owned corporation.

Yang Xiaokai $^{[8]}$ (1997) proposed the evolution theory of division of labor and hierarchical organization when the transaction service efficiency was relatively high, that is, the specialized development will increase the number of transaction structure layers. Sanford Grossman and Oliver Hart mainly discussed the completeness of the contract and the choice of organizational structure. Yu Meng ${ }^{[9]}$ (2013) believed that the adjustment and optimization of industry structure required the upgrading of industrial level and technical level; Wang Guangping $^{[10]}$ (2012) analyzed the adjustment road of China's pharmaceutical industry organizational structure, and proposed two adjustment options, one is differentiation and stratification, the other is merging and reorganization. Luo Cheng ${ }^{[11]}$ (2002) thought that the status and changes of industry structure determined the speed and quality of economic growth, which was largely achieved by the interactive mechanism between technological innovation and industry structure changes. Based on the changes of technological innovation rules caused by EASR, the organizational structure of pharmaceutical industry will be synergistic with the adjustment and transformation of technological innovation, market rules and government organizations. That is, technological changes will inevitably lead to institutional arrangements for the corporation's organizational structure adjustment. 


\subsection{Model Design}

Drug EASR affects the adjustment road and direction of pharmaceutical industry organizational structure. Based on the research paradigm of transaction costs in the new institutional economics, as well as EASR, technological change and innovation environment in the reality, the selection of the adjustment road of pharmaceutical industry organizational structure is closely related with the institutional stability of government's maintaining corporations' code of conduct, rules and procedures.

Science and technology service institutions, the number of incubators, the cost of introducing foreign technology into pharmaceutical industry, the cost of purchasing domestic technology and organizational structure are the main factors affecting the restructuring of medical technology. Technological innovation is the engine of technical and organizational restructuring. The organizational structure indicators related to government innovation support and marketing authorization include: science and technology service industry and the number of incubators, which reflects the level of dependence on the environment of corporations' innovation development. Indicators related to transaction costs between corporations' organizations include: the cost of introducing foreign technology into pharmaceutical industry and the cost of purchasing domestic technology, reflecting the extent of impact of the externality of pharmaceutical technology innovation on the R\&D of pharmaceutical companies. The indicators of the technology transaction market environment include: the technical fee in the contracts of introducing foreign technology and the number of contracts in export-oriented technology regions, reflecting the extent of impact of regional technology transaction development on pharmaceutical R\&D.

Using the number of clinical trial application (Clinic) as the dependent variable to build the Panel Data model, and using the number of science and technology service institutions (Service), the number of technology business incubators (Incubate), the cost of introducing foreign technology into pharmaceutical industry (Outdrug), the cost of purchasing domestic technology (Indrug), the number of contracts in technology transaction market (Contract), the technical fee in the contracts of introducing foreign technology (Outfee) as independent variables, and defining cross-sectional research objects in the 30 provinces or cities such as Beijing $(B J)$, Tianjin $(T J)$ and Hebei $(H B)$, and using the 7-year Panel Data from 2010 to 2016 to establish a basic regression equation for quantitative analysis (formula is as follows); where: $C$ is a constant term, $a$ is a coefficient, $t$ stands for time series, and $i$ represents 30 provinces or cities.

$$
\begin{gathered}
\text { Clinic }_{i t}=a_{0} C_{i t}+a_{1} \text { Service }_{i t}+a_{2} \text { Incubate }_{i t}+a_{3} \text { Outdrug }_{i t}+a_{4} \text { Indrug }_{i t}+ \\
a_{5} \text { Contract }_{i t}+a_{6} \text { Outfee }_{i t} \\
i=B J, T J, H B, \ldots, X J \quad t
\end{gathered}
$$

\subsection{Hypothesis Verification}

The samples were selected in a time dimension of 7 years, and in a section dimension of 30 provinces or cities. Software EViews 7.0 was used to do the analysis. In order to further analyze the correlation and influence degree of relevant factors such as innovation environment and technological change on clinical trial data, an invariant model with no individual influence was adopted. The regression results showed that the regression equation had good goodness of fit, and the adjusted $\mathrm{R}^{2}$ was 0.5583 and the DW value was 2.06 (Table 2). 
Table 2. Regression results of pharmaceutical industry transaction costs on pharmaceutical industry output value

\begin{tabular}{ccccc}
\hline Variables & $\begin{array}{c}\text { Regression } \\
\text { Coefficient }\end{array}$ & $\begin{array}{c}\text { Standard } \\
\text { Deviation }\end{array}$ & t-Statistic & $\begin{array}{c}\text { Ad joint Probability } \\
\text { of T }\end{array}$ \\
\hline C & 0.748843 & 8.947110 & 0.083697 & 0.9334 \\
SERVICE & -0.016451 & 0.020577 & -0.799487 & 0.4254 \\
INCUBATE & 0.303966 & 0.087111 & 3.489411 & 0.0007 \\
OUTDRUG & 0.000362 & 0.001549 & 0.233618 & 0.8156 \\
INDRUG & 0.004187 & 0.000720 & 5.810789 & 0.0000 \\
CONTRACT & 0.002292 & 0.000535 & 4.283033 & 0.0000 \\
OUTFEE & $-3.10 \mathrm{E}-05$ & $3.86 \mathrm{E}-05$ & -0.802989 & 0.4234 \\
\hline \multicolumn{5}{c}{$R^{2}=0.5770$} \\
\hline$W$ value $=2.06$ & $S S E=68.60$ & Adjusted $R^{2}=0.5583$ \\
\hline
\end{tabular}

The results of empirical research showed that: based on the output of pharmaceutical scientific and technological innovations under EASR, that is, from the perspective of the number of clinical trial applications, the number of technology business incubators from various provinces or cities were significantly and positively correlated with pharmaceutical innovation behavior; the number of science and technology service institutions had no correlation with pharmaceutical innovation behavior; the technical fee in introducing foreign technology and the cost of introducing foreign technology into pharmaceutical industry had no correlation with the pharmaceutical innovation behavior; the cost of purchasing domestic technology was significantly and positively correlated with pharmaceutical innovation behavior; the number of contracts in technology transaction market was significantly and positively correlated with pharmaceutical innovation behavior.

\subsection{Results and Conclusion}

Through the regression analysis of the relevant factors of the pharmaceutical industry's technological innovation organizational structure adjustment to the number of new drug clinical trial applications, it revealed the status quo, focus and road of China's pharmaceutical industry organizational structure adjustment under the conditions of EASR.

1) The new drug clinical trials application was significantly and positively correlated with the number of regional technology business incubators. The local support policies of "Mass Entrepreneurship and Innovation" had a positive effect on new drugs' R\&D. The government adopted a him-organized behavior to provide substantial support and services to medium-sized, small-sized and micro biomedicine corporations, which would enhance the innovation performance of pharmaceutical industry. Science and technology service institutions should adapt to the development trend of biomedical innovation's specialization and transform into specialized service organizations.

2) The foreign technology introduction behavior by pharmaceutical corporations did not have the externality of technological innovation, while the purchase of domestic technology transfer had a significant and positive correlation with the corporations' application of clinical trials, that is, domestic new drug technology transfer and technology authorization will play a more active role in improving the performance of biomedical technology innovation. Therefore, the recognition of overseas data under EASR and the institutional arrangements for the globalization of $R \& D$ will exert some pressure on new drug R\&D by domestic corporations. It will require specialized service institutions to increase support for medium-sized, small-sized and micro corporations and to pay attention to technology transfer and technology authorization in domestic pharmaceutical industry.

3) Good macro-environmental conditions for technology transfer and technology authorization will drive technology transfer in the pharmaceutical technology market, which will have a positive impact on new drug clinical trial application. But the introduction of foreign technical services has failed to improve the performance of new drug R\&D. The recognition of overseas multi-center clinical trial data may reduce the expectation of technology transfer of overseas corporations. Therefore, provinces and cities should further increase the policy support for domestic medical technology transfer and technology authorization, and propel the evolution of corporation or social technology service institutions into medical technology transfer service platform. 


\section{Optimization Road of Pharmaceutical Industry Organizational Structure under EASR}

\subsection{Specialized Division Mode}

Based on the advantages of rich domestic clinical resources, good basis for GMP transformation and low labor cost within China, China is becoming an important base for global contract R\&D and contract production ${ }^{[12]}$. The FDA's "Critical Path Initiative" for innovative drug was used as a template and CRO as the organization form to design the organizational structure in China's research field (Figure 12). Based on the positive correlation between new drug clinical trial applications and domestic technology transfer, CRO specialization was subdivided into a domestic pharmaceutical technology transfer service platform, and was synergized with local technology business incubators to jointly enhance the innovation performance of the biomedical industry. Currently, universities and state-owned research institutions are the main force to generate outstanding performance in China's pharmaceutical innovation field. Only a small number of corporations cooperating with CRO have achieved remarkable results in innovation field. Therefore, pharmaceutical cooperation and social organizations adopted a self-organizing behavior, put the transfer and transformation of scientific and technological achievements of "Internet $+"$ as the core to build and perfect regional centers for medical technology transfer so as to propel organizational structure adjustment, transformation and upgrading in the pharmaceutical industry.

\begin{tabular}{|c|c|c|c|c|c|}
\hline $\begin{array}{c}\text { Research } \\
\text { Links }\end{array}$ & Basic research & Drug design & GLP phase & GCP phase & Approval \\
\hline Market & Universities, & Universities, CRO, & Research & Research & Universities, \\
Entity & Research & Scientific and & Universities, & Institutions and \\
& Institutions & Technological & Corporations, & Corporations \\
& & Institutions & CRO & \\
& & & \multicolumn{3}{|c|}{ Evaluation \& Approval } \\
\hline
\end{tabular}

\begin{tabular}{|c|c|c|c|c|}
\hline Safety & $\begin{array}{l}\text { API Selection } \\
\text { Structure-Activity } \\
\text { Relationship }\end{array}$ & $\begin{array}{l}\text { In vitro and } \\
\text { Animal Trials }\end{array}$ & $\begin{array}{l}\text { Human and } \\
\text { Animal Trials }\end{array}$ & $\begin{array}{l}\text { Follow-up } \\
\text { on Safety }\end{array}$ \\
\hline Clinical & $\begin{array}{l}\text { In vitro and } \\
\text { Computer Aided } \\
\text { Evaluation }\end{array}$ & $\begin{array}{l}\text { In vitro and } \\
\text { Animal Trials }\end{array}$ & $\begin{array}{l}\text { Evaluation of } \\
\text { Effectiveness to } \\
\text { Human }\end{array}$ & \\
\hline $\begin{array}{c}\text { Manufacto } \\
\text { ry }\end{array}$ & Early Intervention & $\begin{array}{l}\text { Phase III } \\
\text { Clinical Trial } \\
\text { Small Batch } \\
\text { Production }\end{array}$ & $\begin{array}{l}\text { Groping Process } \\
\text { Refining } \\
\text { Parameters }\end{array}$ & $\begin{array}{l}\text { Mass } \\
\text { Production }\end{array}$ \\
\hline
\end{tabular}

Figure 12. Organizational structure in pharmaceutical R\&D field based on specialized division

\subsection{Organizational Mode under Big Data}

At present, the accumulation of regulatory data in the drug safety management system is growing rapidly, but the relevant data analysis and data mining work such as clinical verification, supervision and auditing, administrative authorization, flight inspection, etc. has not been carried out deeply. It results in poor added-value to data in that only very limited data can be provided to evaluate drug quality in the aspect of monitoring risk, spot check and inspection for evaluation purpose or GQCE. The clinical trial data management system should be capable of providing real and traceable data for clinical trial. In May 2007, the FDA issued the Guidance for 
Industry: Computerized Systems Used in Clinical Investigations; in Oct. 2005, the International Society of Clinical Data Management developed the Good Clinical Data Management Practices (GCDMP); both in the efforts to achieving risk monitoring in the process of drug clinical trial, production and operation data quality management, providing data support to facilitate decision-making for EASR.

\subsection{Cooperation and Communication Platform among Countries}

Under the dual pressure of overseas multi-center clinical trial data being recognized and CFDA becoming official member of $\mathrm{ICH}$, domestic new drug evaluation and approval standards and R\&D resource allocation have now been exposed in front of the world. Establishing international cooperation and communication platform nationwide or region-wide has become an irresistible trend. In Aug. 2016, the 13th Five-Year National Science and Technology Innovation Plan (Guo Fa [2016] No. 43) proposed that "optimizing the allocation of innovative resources globally, combining scientific and technological innovation with national diplomatic strategies, promoting the establishment of a broad Community of Innovation." Facing domestic GQCE project squeezing clinical resources and sudden increase in R\&D cost due to "two-invoice system \& camp changed to increase" policy, many domestic corporations adopted the "going out" strategy to implement international mergers and acquisitions. The national cooperation and communication platform in the field of medical innovation has gradually evolved into the self-organizing behavior of pharmaceutical companies. The cross-border mergers and acquisitions by pharmaceutical companies to form a new corporation organizational structure, and the internalization of foreign medical technology into internal behavior of Chinese corporations, are both alternative roads to introducing foreign technology and enhancing the performance of new drug R\&D.

\subsection{Solidified Mode by MAH}

The introduction of the MAH (Marketing Authorization Holder) system separates marketing authorization from production authorization which is beneficial to the effective integration of $\mathrm{R} \& \mathrm{D}$ and production resources. CMO (Contract Manufacture Organization) / CDMO (Contract Development Manufacture Organization) will become more popular as a development model in the field of R\&D. As an important institutional arrangement for drug regulatory administrative authorization, the MAH system is a major change in the government's asset-centered drug regulatory mode. It divides the property rights of $R \& D$ results into ownership, production rights, sales rights and so on. It confirms the rights of $R \& D$ institutions that participate in scientific research activities, as well as R\&D timing and R\&D rights and interests, solidifying explicit system and implicit rules in R\&D field. At present, the MAH system is mainly used to solve the overcapacity problem and drug full lifecycle management in GQCE. On one hand, the MAH system has solidified the rights and interests of market organizations, and on the other hand, it has put forward more strict requirements for knowledge management under the separation of medical property rights. The MAH system will inevitably accelerate the emergence of institutions in third-party inspection, certification, evaluation, training and so on in pharmaceutical industry.

\subsection{The Combination of Technology and Finance}

The technology business incubator is a service organization that fosters and supports small and medium-sized high-tech corporation. The National Science and Technology Business Incubator's 13th Five-Year Development Plan proposed "incubation resources to be basic, innovative technologies to be capitalized, capital for incubation to be intensive" to "meet those start-up entrepreneurs' needs of funds". The combination of science and technology with finance will realize the adjustment, transformation and upgrading of organizational structure in pharmaceutical industry under the changes of EASR. The technology business incubators united with professional institutions will be upgraded and transformed into a specialized technology service model to enhance the performance of new drug $R \& D$ in pharmaceutical industry. At present, the shortage of domestic clinical trial resources, the increase in labor costs and the high standards of evaluation and approval have led to high $R \& D$ cost. The related resource allocation such as corresponding R\&D foundation, technology platform and financial support is needed to stimulate $\mathrm{R} \& \mathrm{D}$ vitality of domestic pharmaceutical companies, to invigorate domestic medical technology transfer market and to improve the performance of new drug R\&D. The combination of science and technology with finance will propel the innovation and entrepreneurship of the pharmaceutical industry to be more efficient and convenient.

\section{Conclusion}

EASR is playing an important role in such problems as the innovation performance of the pharmaceutical industry, the transformation of technological achievements, the management of medical knowledge and the improvement of core competitiveness. The achievements in both the adjustment and optimization of pharmaceutical industry organizational structure and institutional arrangement will propel the rationalization and marketization of corporations' innovative behaviors. Based on the important opportunity in drug EASR and the 
globalization of R\&D activities, on one hand, the organizational structure in pharmaceutical industry could be stratified and the rules between organizations in the corporations could be solidified, and on the other hand, the market leading and stabilization role of the state-owned corporations in a him-organized form could be brought into play in EASR.

\section{References}

Coase, R. (1937). The nature of the firm. Economical, (4), 386-405. https://doi.org/10.1111/j.1468-0335.1937.tb00002.x

Klein, B., Crawford, R., \& Alchian, A. (1978). Vertical Integration, appropriable rents and the competitive contacting process, (21), 297-326.

Lin, Y. F., Cai, F., \& Li, Z. (1997). Full information and reform of state owned enterprises. Shanghai: Shanghai Joint Publishing.

Luo, C., \& Yang, X. Y. (2002). Technical innovation and industrial structural adjustment in our country. Lanzhou Academic Journal, (3), 19-21.

Malerba, F. (2006). Innovation and dynamics and evolution of industries: Progress and challenges. International Journal of Industrial Organization, (24), 1-25.

Malerba, F. (2006). Innovation and dynamics and evolution of industries: Progress and challenges. International Journal of Industrial Organization, (24), 1-25.

Ren, Z. H., \& Feng, G. Z. (2008). Innovative drug R\&D industry chain and specialized division of labor. Chinese Journal of Pharmaceutical Technology Economicees and Management, 2(8), 39-43.

Simon, H. A. (1957). Administrative Behavior. New York: Free Press.

Wang, G. P., Ding, D., \& Zhang, X. P. (2012). Research on the organizational restructuring of Chinese pharmaceutical industry during the period of the 12th five-year plan. Chinese Pharmaceutical Affairs, 26(10), 1060-1065.

Williamson, O. E. (1985). The economic Institutions of Capitalism. New York: Free Press.

Yang, X. K., \& Zhang, Y. S. (2000). New classical economics and inframarginal analysis. Beijing: China Renmin University Press.

Yu, M., \& Liu, J. Q. (2013). Innovation, financial development and industrial structural optimization. Management and Administration, (1), 74-77.

Zhang, W. Y. (1995). An entrepreneurial: Contractual theory of the firm. Shanghai: Shanghai Joint Publishing.

\section{Copyrights}

Copyright for this article is retained by the author(s), with first publication rights granted to the journal.

This is an open-access article distributed under the terms and conditions of the Creative Commons Attribution license (http://creativecommons.org/licenses/by/4.0/). 